\title{
“É PRECISO GRITAR BEM ALTO”: resistência, nacio- nalismo e libertação timorense em Francisco Borja da Costa
}

\author{
Regina Helena Pires de Brito \\ (Universidade Presbiteriana Mackenzie) \\ https://orcid.org/0000-0002-0634-8572 \\ Vima Lia de Rossi Martin \\ (USP) \\ https://orcid.org/0000-0002-8533-475X
}

\section{RESUMO}

Este artigo objetiva contextualizar e analisar uma série de catorze poemas escritos pelo timorense Francisco Borja da Costa (19461975), publicados em 2009, em Portugal, numa edição bilíngue (português/tétum), por seu irmão Luís Costa, estudioso de cultura timorense e especialista na língua tétum, língua oficial ao lado do português em Timor-Leste.

PALAVRAS-CHAVE: literatura timorense; Francisco Borja da Costa; Timor-Leste; Estudos Lusófonos.

\section{"É PRECISO GRITAR BEM ALTO": resistance, nationalism and liberation of the Timorese people in Francisco Borja da Costa}

\section{ABSTRACT:}

The objective of this article is to contextualize and analyze a series of fourteen poems written by the Timorese Francisco Borja da Costa (1946-1975), published in 2009 in Portugal, in a bilingual (Portuguese and Tetum) edition, by his brother Luis Costa, a scholar of Timorese culture and a specialist of the Tetum language, official language, along with Portuguese, of East Timor.

KEYWORDS: Timorese literature; Francisco Borja da Costa; East Timor; Lusophone Studies. 
[...] Francisco tinha outras ambições que passavam por um futuro diferente para a sua ilha. Como muitos jovens da mesma geração, ligou-se aos grupos políticos que queriam a independência para o território. Foi um dos fundadores da FRETILIN e o seu nome estava numa lista de gente a abater que os indonésios já levavam na invasão. Era um homem discreto, extremamente magro, de olhos vivos, amável e conversador, embora cheio daquela reserva polida que os timorenses demonstram sempre nos primeiros contatos. No fundo da alma, era diferente de muitos outros de seu tempo. A par da paixão pela ilha onde queria ver nascer um país a sério, amava a literatura, a escrita e a poesia. (FERNANDES, 2001, p. 149)

\section{Primeiras palavras}

A literatura timorense é bastante jovem, tendo em vista o panorama das literaturas de língua portuguesa. De fato, a história da literatura escrita nesse território inicialmente povoado por diferentes grupos étnicos, majoritariamente descendentes e melanésios e malaio-polinésios, é recente. Entretanto, a tradição oral, assentada em modos próprios de organização e transmissão de saberes, é forte entre os timorenses e, nesse sentido, a diversidade cultural inscrita nas práticas da oralidade das várias etnias que compõem o país são altamente significativas.

Nesse contexto, a produção de textos literários escritos, seja em português seja em tétum (língua nacional e oficial, ao lado da portuguesa), frequentemente dialoga com aspectos das culturas orais, especialmente por meio da apropriação de soluções formais bastante características, como o rigor métrico, responsável pelo ritmo, e as repetições. Assim, diversas narrativas e poemas, enraizados na palavra falada, se constroem como uma forma de resistência à hegemonia dos discursos de matriz europeia, afirmando a complexidade social e cultural de uma nação forjada sob os imperativos da ação colonial portuguesa.

Tendo essa realidade em perspectiva, o objetivo deste artigo é contextualizar e analisar uma série de catorze poemas escritos pelo timorense Francisco Borja da Costa (1946-1975), publicados em 2009 em Portugal por seu irmão Luís Costa, estudioso de cultura timorense e especialista na língua tétum. Para tanto, dividiremos as reflexões em três momentos: inicialmente, teceremos algumas considerações sobre a relação existente entre literatura e resistência, de maneira especial em períodos recentes de combate ao colonialismo; na sequência, apresentaremos informações 
sobre o autor timorense e sua obra, dando destaque a aspectos singulares de seu contexto de produção e de seu projeto literário; e, por fim, focalizaremos os poemas, buscando evidenciar seus eixos temáticos e algumas estratégias formais.

\section{Poesia e resistência}

Em seu texto "Narrativa e resistência", Alfredo Bosi observa que o conceito de resistência se origina no campo da ética e não da estética. Isso significa considerar que são sobretudo os valores (e os antivalores) - forças catalisadoras da vida em sociedade - que são representados pelo escritor, segundo opções estéticas próprias e inclinações ideológicas específicas. Nas palavras de Bosi: "Não são os valores em si que distinguem um narrador resistente e um militante da mesma ideologia. São os modos próprios de realizar esses valores." (BOSI, 2002, p.123)

Assim sendo, o escritor empenhado, que dialoga diretamente com a realidade social, posicionando-se criticamente diante dela, confere uma dimensão explicitamente ética ao seu texto, inserindo-o em um contexto de resistência política. As reflexões de Bosi, ainda que ancoradas na observação de textos escritos em prosa, podem ser estendidas para o âmbito da poesia, uma vez que destaca a posição ideológica do escritor, materializada no modo como trata, ou representa, em sua produção literária, os valores sociais.

Em contextos de dominação colonial, as resistências política e cultural se articulam de forma estreita, constituindo-se em instrumento de luta para o fim da exploração e da opressão e para a conquista de uma identidade cultural autônoma em relação àquela imposta pelo colonizador. Benjamin Abdala Jr. chama a atenção para as especificidades dessa luta, inserida em condições de subdesenvolvimento e marcada por um impulso modernizante: "A identidade cultural dos países colonizados mostra-se por uma luta que não se esgota na independência política. É uma conquista contínua de uma autodeterminação a efetivar-se dentro das condições de subdesenvolvimento e de necessidade de modernização." (ABDALA Jr., 2007, p.51).

Nessa perspectiva, o verso que destacamos no título deste artigo (“É PRECISO GRITAR BEM ALTO”), que integra as estrofes finais do poema "O povo Maubere não pode ser escravo de mais ninguém" - caraterizado por Luís Costa como um verdadeiro "grito de liberdade" (COSTA, 2009, p. 6) -, é representativo dessa articulação entre as forças de 
resistência política e cultural para a denúncia da exploração e para o brado da conquista da liberdade. Nesse poema, já com título inflamado e imperativo, Borja da Costa se vale de letras (literalmente) maiúsculas e de uma repetição que ecoa, nos quatro últimos versos - "DE MAIS NINGUÉM" -, o desejo manifesto do poeta e revolucionário, referindo-se tanto ao domínio colonizador europeu, quanto à iminente ameaça indonésia que já se anunciava no início dos anos de 1970:

\section{[...]É PRECISO GRITAR BEM ALTO \\ QUE O POVO DE TIMOR \\ QUE O POVO MAUBERE \\ NÃO PODE SER ESCRAVO \\ DE MAIS NINGUÉM}

\section{DE MAIS NINGUÉM \\ DE MAIS NINGUÉM \\ DE MAIS NINGUÉM.}

Se ampliarmos nosso olhar para as realidades imediatamente pré e pós independência de outro países colonizados por Portugal, como Angola, por exemplo, é possível estabelecer paralelos entre o compromisso político - e estético - assumido por poetas militantes desse país africano, como Agostinho Neto, Costa Andrade ou Manuel Rui, e o poeta timorense Borja da Costa. Ainda que as singularidades vividas nos contextos angolano e timorense distanciem os autores e suas produções - especialmente no que se refere às forças políticas em jogo e ao papel político e militar exercido por Portugal -, constantes discursivas, comprometidas com a demonstração da resistência política e capazes de expressar um imaginário político de inclinação popular, podem ser observadas em poemas que se voltam tanto para a exortação da independência, quanto para a afirmação de uma identidade nacional ansiada.

Parâmetros concretos que balizaram a produção de intelectuais e escritores empenhados na emancipação de seus territórios podem ser notados, por exemplo, em documentos como a "Proclamação", que marcou, em Angola, a constituição da União dos Escritores Angolanos (UEA), associação fundada em 10 de dezembro de 1975 que agregou e ainda continua a reunir autores do país.

A "Proclamação", reconhecida em Luanda pelos então membros da nascente UEA, como Luandino Vieira, Arnaldo Santos, António Jacinto, 
Jofre Rocha, entre outros, reafirma a convicção de que apenas de forma coletiva e organizada os escritores poderiam, de fato, contribuir para a formação da consciência e a emancipação de seu povo. Para tanto, os signatários do texto postulam os seguintes princípios:

1. A necessidade e a urgência de defender a especificidade cultural do homem angolano, em especial de salvaguardar as suas tradições culturais historicamente perspectivadas e garantidas por séculos de resistência popular, e as conquistas culturais obtidas ao longo da independência nacional;

2. A necessidade e a urgência de ativar, a partir dessas tradições e conquistas, o inventário cultural do país no contexto particular do renascimento cultural africano como contribuição original para um mundo verdadeiramente livre;

3. A necessidade e a urgência de os escritores se organizarem coletivamente para prosseguirem nesta longa luta do nosso povo para a conquista de um futuro digno, liberto de todas as formas de alienação, exploração e dependência, numa sociedade democrática e progressista. (NETO, 1978, p.26)

Os três itens constituem-se como uma espécie de orientação para os escritores envolvidos com a emancipação de seu país que, recém-independente, carecia de uma "estabilização cultural" assentada em bases não coloniais. Em outras palavras, carecia de uma literatura que, escrita por homens já livres do jugo colonial, inventariasse um repertório cultural relacionado, sobretudo, à salvaguarda das chamadas "tradições" e ao registro da longuíssima história de resistência ao colonialismo.

Tratava-se, evidentemente, de uma busca por afirmação identitária, pautada por aspirações utópicas que imaginaram, por meio da reescrita da história do "homem angolano" e do próprio país, a possibilidade de conquistar um futuro socialmente menos injusto - "um mundo verdadeiramente livre". É desse modo que se efetiva, em parte da literatura produzida em Angola no contexto da independência política, a resistência assinalada por Bosi. Nessa mesma direção, a respeito da produção literária timorense, Benjamin Abdala Jr. esclarece:

[...] Mais do que emblema da resistência do povo timorense, a atividade literária em língua portuguesa constitui hoje manifestação simbólica da forma como ele se imagina enquanto nação, por meio da mediação de seus escritores. Na verdade, o próprio horizonte nacional 
timorense, que supera os particularismos étnicos, é construção dessa intelectualidade. (ABDALA Jr., 1997, s/p).

E é nessa mesma direção que podemos ler, guardadas as diferenças, a produção poética de Francisco Borja da Costa. Segundo Luís Costa, a obra do poeta timorense apresenta

[...] a influência dos movimentos de libertação africanos e dos estudantes da Casa de Timor em Lisboa, bem como a percepção das injustiças e desigualdades com que se foi deparando na convivência com os portugueses na tropa e na administração pública. As poesias de Borja da Costa onde se nota um deslumbramento por Pablo Neruda, Marx (luta operária), Mao Tse Tung e Samora Machel, foram escritas sobretudo para sensibilizar o povo explorado [...]. (COSTA, 2009, p.5-6)

Dessa maneira, os gestos de afirmação identitária e de defesa das culturas locais como patrimônio nacional são eminentemente políticos e se presentificam, de maneira própria e singular, nos poemas deixados por Borja da Costa.

\section{Borja da Costa e a libertação timorense}

Embora restrita e pouco divulgada, a produção literária escrita timorense apresenta nomes de relevo como Xanana Gusmão, na poesia, e Luís Cardoso, na prosa. De fato, não é fácil encontrar obras timorenses: as poucas publicações estão dispersas geográfica e linguisticamente e, certamente, devem existir inéditos que agora, em condições políticas mais favoráveis, podem começar a aparecer. No rol dos escritores comumente referidos, além de Borja da Costa, encontram-se Fernando Sylvan, Jorge Lautem, Abé Barreto, Ponte Pedrinha, José Barros Duarte, João Aparício, Paulo Quintão da Costa, Maria Alice Branco, Filomena de Almeida e Cristina Lopes (exemplos de vozes femininas da diáspora), dentre outros.

Especialmente na literatura que se revela em Timor-Leste após a Revolução dos Cravos - que, no contexto timorense, significou o fim da dominação portuguesa, a 28 de novembro de 1975, e o princípio do domínio indonésio, iniciado com a invasão a Timor-Leste a 7 de dezembro do mesmo ano e que se arrastou por um período de 24 anos-, transparece forte realismo, combinando a temática da luta pela libertação com jogos de imagens denunciadoras dos preconceitos contra o povo timorense, da angústia pelo silenciamento provocado pelo colonizador, da consternação diante da exclusão social e da pobreza, da dor pelos castigos e mortes arbitrárias. 
Francisco Borja da Costa nasceu em 1946, em Fatu-Berliu, Manatuto, e fez no Colégio de Soibada a instrução primária; continuou seus estudos em Dare, na capital Dili, chegando a frequentar o importante Liceu Francisco Machado, sem, entretanto, concluir sua formação. Trabalhou no funcionalismo público, na categoria de aspirante da Repartição de Gabinete. Desde cedo, seu talento literário e seu respeito às tradições culturais timorenses se fazem notar; tanto que, por volta de 1970, quando portugueses identificados com a ideologia colonial começam a ridicularizar as culturas autóctones de Timor-Leste, "um grupo de intelectuais timorenses - Xavier do Amaral, Nicolau Lobato, Borja da Costa e, mais tarde, o português Inácio de Moura - começou a publicar artigos no Boletim Diocesano SEARA, debatendo e contestando o desrespeito pela cultura tradicional do povo" (COSTA, 2009, p.5). Esse debate cultural muito rapidamente passou a ser, também, uma questão política e o SEARA foi fechado. Nessa direção, vale o registro de Xanana Gusmão (1994):

Borja da Costa começava a escrever uns artigos e dava-me a ler, trocávamos impressões e convenceu-me.

Não eram artigos incisivos, eram metáforas da situação, que desejavam esboçar uma sociedade de três mundos, dos colonialistas, dos assimilados e da população. A censura deu sinal de si e apenas publicou 2 artigos dele em que foram poupadas somente as descrições imaginárias já sem conteúdo... (GUSMÃO, 1994, p. 10)

Em 1973, Borja da Costa passa um período em Lisboa, onde, além de estagiar nos jornais Diário de Lisboa e Popular, frequenta a Casa de Timor e conhece os movimentos de libertação africanos, sendo que essa vivência proporciona a ele "experiência e liberdade de expressão jornalística e poética" (COSTA, 2009, p.5). Esses acontecimentos foram decisivos para sua participação ativa no movimento nacionalista e para seu engajamento na Associação Social Democrática Timorense (ASDT), criada em maio de 1974 e transformada na FRETILIN - Frente Revolucionária de Timor-Leste Independente, em setembro daquele ano.

Entre agosto e novembro de 1975, muita instabilidade social e política é enfrentada pela população timorense, uma vez que a FRETILIN e a UDT (União Democrática Timorense) se confrontam pela liderança do território. A disputa é vencida pela FRETILIN, que declara a independência de Timor-Leste em 28 de novembro de 1975, a despeito da presença das milícias indonésias nas fronteiras, prontas para uma invasão. Esse 
primeiro período de independência foi extremamente curto e teve um desfecho dramático, conforme descreve o jornalista Fernando Lima:

Às primeiras horas de 7 de Dezembro, forças navais indonésias começaram a bombardear as costas a Leste e Oeste de Díli, na presunção de que, desse modo, atingiriam posições da FRETILIN nos arredores da cidade. Pouco depois, cerca das cinco da manhã, chegavam os aviões com tropas paraquedistas que tomariam de assalto a capital e abririam fogo, indiscriminadamente, sobre os civis que lhes surgiam pela frente. Os relatos de então dão conta de autênticos massacres da população civil, praticados pelos soldados invasores, a que não faltaram chocantes cenas de pilhagens. (LIMA, 2002, p. 258).

Relativamente ao destino de Borja da Costa, completam o relato do jornalista, as palavras de Luís Costa:

No dia 7 de dezembro de 1975, como a maioria dos responsáveis da Fretilin, Borja da Costa também não acreditou na invasão indonésia como anunciara, muitas vezes, a UDT [União Democrática Timorense] através da Rádio Kupang. Assim, nessa madrugada, desprevenido e sem possibilidade de fugir para as montanhas como o saudoso Nicolau Lobato e outros membros do movimento nacionalista, Borja da Costa e um companheiro foram assassinados à frente da sua residência em Kolan-ibun, Bairro dos Grilos. O seu corpo, juntamente com o de outros membros da Fretilin e da Apodeti (Associação Popular Democrática de Timor) foi lançado ao mar, tendo sido enterrado, posteriormente, na praia entre Lecidere e a ponte Santana, segundo dizem, ao pé de um coqueiro. (COSTA, 2009, p. 5)

O assassinato de Borja da Costa atesta a violência das forças indonésias que, com o apoio dos Estados Unidos e da Austrália, invadem Timor-Leste com a justificativa de conter o comunismo. A manobra foi repudiada pela comunidade internacional, mas consolidou formas de opressão e exploração que deixaram marcas densas e profundas na sociedade timorense. Como se sabe, somente em 1999 (com a entrada das Forças de Paz das Nações Unidas e o período de Administração Transitória da ONU em Timor-Leste), o país começou a trilhar caminhos para a independência (assinalada, oficialmente, a 20 de maio de 2002) e deu início a uma reorganização da nação em bases democráticas.

Os poemas que compõem a "Selecção de Poemas - Kilbur Dadolin" correspondem, segundo Luís Costa, ao conjunto integral da produção poética de Borja da Costa, acreditando esse estudioso que, embora vez ou outra queiram atribuir ao irmão a autoria de algum poema de autor des- 
conhecidos, não haja mais nenhum inédito. Luís Costa assinala, na quarta capa da obra, que

Os poemas de Borja da Costa transcrevem a sua rebeldia educacional e religiosa a par com as ideias revolucionárias de então e foram escritos para sensibilizar o povo explorado, combinando as formas tradicionais (cantigas para o tebe/dahur) com as ideias nacionalistas. A linguagem de seus poemas está enquadrada no espírito da época anti-colonial e na luta social através da revolução, onde não são esquecidos os problemas regionais a nível educacional e do desenvolvimento. (COSTA, 2009, quarta capa).

Ecoando sua posição lúcida e combativa (e ideologicamente influenciado pelas teorias maoístas), os versos de Borja da Costa, que também é autor do Hino Nacional Timorense ${ }^{1}$, assassinado aos 29 anos, denunciam a dominação colonial, exaltam a liberdade e trazem reflexões acerca da necessidade imperativa da conscientização política e da edificação essencial de uma identidade nacional timorense.

\section{4. "Acorda, que a madrugada já desponta!"}

Os catorze poemas de Borja da Costa foram compilados em 2009, por Luís Costa, na edição bilíngue da editora Lidel: Borja da Costa - selecção de poemas / klibur dadolin. Cada um deles, bem como os paratextos que compõem o livro - biografia de Borja da Costa; nota prévia; certidão de batismo e cartão de identificação do poeta; e bibliografia aparecem registrados em tétum e português, em versão de Luís Costa. A obra apresenta, ainda, uma série de nove fotografias, em preto e branco, de paisagens naturais do espaço timorense que aparecem intercaladas aos textos. Lucia Vidal Soares destaca, quando do lançamento da obra, que

Como acontece com muitos outros autores da denominada "Literatura de Expressão Portuguesa” (ainda que esta designação seja contestada),

\footnotetext{
${ }^{1}$ Trata-se do poema "Pátria, Pátria", constante da coletânea e que segue transcrito: Pátria, Pátria / Timor-Leste, nossa Nação / Glória ao Povo e aos heróis / Da nossa libertação. / Vencemos o colonialismo / Gritamos, abaixo o Imperialismo / Terra livre, Povo livre / Não, não, não, à exploração. / Avante unidos / Firmes e decididos / Na luta contra o Imperialismo / O inimigo dos Povos / Até à vitória final / Pelo caminho da Revolução. / Pátria, Pátria! Timor-Leste, nossa Nação / Glória ao Povo e aos heróis / Da nossa Libertação.
} 
manifesta veementemente o seu desejo independentista, o amor ao seu povo, à sua cultura e tem consciência da injustiça social a que os timorenses estavam sujeitos (pobreza, fome, iliteracia, humilhação, abuso, falta de liberdade, etc.). A sua poesia conjuga, no aspecto formal, um enorme entrosamento com as formas poéticas tradicionais timorenses pela utilização de: paralelismo (poemas 1 e 2), refrão (poema 6), jogos de palavras (poema 3), gradação (poema 6), metáforas, anáforas e com aspectos culturais timorenses, como seja: a associação da poesia à música e à dança e a situações de interacção social, formal e informal, tais como as cerimónias fúnebres (sidon) [...] ou ainda em situações laborais em que homens e mulheres cantam à desgarrada, enquanto tratam do milho ou do arroz. (SOARES, 2009, s/p).

A preferência por uma edição bilíngue, opção do autor da coletânea, marca, de saída, também uma opção política, um sinal de afirmação da identidade timorense, pautada no uso e na difusão daquela que é a língua mais falada pela população - o tétum -, ao lado da língua portuguesa, que, como dissemos, também é oficial no país. De certo modo, respeita o próprio fazer poético de Borja da Costa, que se expressava poeticamente com segurança em ambas as línguas.

A opção política pelo uso do tétum está presente na elaboração de cinco dos catorze poemas de Borja da Costa que, ao afirmar o uso dessa língua como língua literária, não apenas estabelece uma interlocução direta com os seus falantes, mas também assinala uma memória cultural que se quer preservar e valorizar, inserindo-a na série literária. Nos outros momentos, o poeta prefere a expressão em língua portuguesa pensando no público que desejava atingir: aqui, não fala somente aos timorenses, mas se abre também para quaisquer leitores de língua portuguesa.

Os textos são apresentados lado a lado, sempre nas duas línguas, embora os originais tenham sido escritos por Borja da Costa conforme a tabela 1 que se segue (a numeração corresponde à apresentada na coletânea): 


\begin{tabular}{|c|l|l|}
\hline \multicolumn{1}{|c|}{ Título do poema no original } & \multicolumn{1}{c|}{$\begin{array}{c}\text { Título do poema na } \\
\text { tradução }\end{array}$} \\
\hline 1 & Foho Ramelau & Monte Ramelau \\
\hline 2 & $\begin{array}{l}\text { O povo Maubere não pode ser escravo de } \\
\text { mais ninguém }\end{array}$ & $\begin{array}{l}\text { Povu Maubere la bele } \\
\text { tenki ema seluk nia atan }\end{array}$ \\
\hline 3 & O rasto da tua passagem & Tuir o ain klor \\
\hline 4 & Povu kiak & Povo pobre \\
\hline 5 & Kole lele mai (sa sa ha'a nalo) & $\begin{array}{l}\text { Kole lele mai (o que é } \\
\text { que faz?) }\end{array}$ \\
\hline 6 & Kdadalak & Regatos \\
\hline 7 & O grito do soldado maubere & $\begin{array}{l}\text { Soldadu maubere nia } \\
\text { lian }\end{array}$ \\
\hline 8 & Ela vencerá & Feto sei manán \\
\hline 9 & Um minuto de silêncio & Nonók minutu ida \\
\hline 10 & O amor & Domin \\
\hline 11 & Pátria, Pátria & Patria, Patria \\
\hline 12 & Os ventos do teu dorso & Anin susuut o kotuk \\
\hline 13 & Fitu mutin & Estrela d'Alva \\
\hline 14 & Demagogicamente & Hateten ibun boboot \\
\hline & & \\
\hline
\end{tabular}

Tabela 1 - títulos dos poemas no original e na tradução de Luís Costa

Quanto à ordenação dos poemas, esta não corresponde a nenhuma sequência cronológica, mas sim a uma opção estética do autor do volume. Teceremos, a seguir, alguns comentários mais individualizados sobre alguns dos textos que julgamos representativos do projeto literário do autor, marcado pela criação de imagens fortes e pelo uso de uma linguagem incisiva e exortativa.

O verso "Acorda, que a madrugada já desponta!", subtítulo que nomeia esta seção do artigo, encontra-se no primeiro poema da coletânea, tendo sido escrito originalmente em tétum e posteriormente traduzido pelo próprio Borja da Costa. Seu título, "Foho Ramelau", refere-se à montanha mais alta da ilha de Timor e ao ponto mais alto do país. Como indicado em nota de rodapé na coletânea, o texto foi musicado por Abílio Araújo e ficou consagrado como o hino da revolução da FRETILIN, sendo que sua melodia se desenvolve conforme as melodias tradicionais timorenses, em movimento ascendente, de modo a sugerir "a saída do obscurantismo 
para aceder à libertação" (COSTA, 2009, p.13). Vale registrar, ainda, que em língua mambai, falada na região onde se situa o monte, ele é conhecido como Tatamailau e significa "o avô dos montes". No texto, o pico aparece personificado, sendo que o poeta, depois de reverenciar a sua imponência e grandiosidade, exorta-o a acordar e a tomar conta de seu próprio destino, ou seja, sugere a autodeterminação do povo timorense. A fim de evidenciar os efeitos de sentido obtidos por meio de expedientes expressivos, marcados pelo recurso ao imperativo, pela opção por pontuação rica em exclamações e interrogações, pela escolha da onomatopeia “oh" pela insistência enfática da repetição, tão presente neste e em outros poemas do conjunto, optamos por reproduzi-lo na íntegra

\section{Monte Ramelau}

Oh! monte Ramelau, monte Ramelau oh!

O que é mais alto que o teu cume, O que é maior que a tua imponência!

Porque é que o timorense há-de curvar a cabeça para sempre?

Porque é que o timorense há-de ser escravo para sempre?

Porque é que o timorense há-de curvar-se para sempre?

Porque é que o timorense há-de ser escravo para sempre?

Acorda, que a madrugada já desponta!

Acorda, que o novo dia já desponta!

Abre os olhos, o novo dia chegou à tua aldeia

Abre os olhos, o novo dia chegou à nossa terra

Acorda, toma conta do teu destino oh!

Acorda, governemos nós próprios a nossa terra oh!

Acerca deste poema, Benjamin Abdala Jr. (1997), numa rara referência à literatura de Timor-Leste ainda na época do domínio indonésio, destacou a referência identitária nacional que o Ramelau simboliza:

Ramelau é uma cadeia montanhosa, onde se encontra o pico Tata-Mai-Lau, igualmente referenciado como símbolo da identidade nacional dos timorenses. Nesse pico, segundo a tradição animista, estariam os antepassados dos timorenses. Essas referências simbólicas de identida- 
de, de caráter neo-romântico, são singularidades geográficas altamente frequentes numa literatura que procura se reconhecer. (ABDALA Jr. $1997, \mathrm{~s} / \mathrm{p})$

No segundo texto, "O povo Maubere não pode ser escravo de mais ninguém", o poeta Borja da Costa clama pela liberdade para o povo maubere, criando imagens que remetem à dificuldade da sobrevivência no campo e, ao mesmo tempo, apontando a possibilidade de superação da dominação provocada pelo colonizador português, responsável pelo medo servil dos colonizados. Note-se que nesse poema e em outros o autor prefere usar "maubere" a "timorense", marcando sua opção política por um termo que enfatiza a memória do povo oprimido e sua tradição cultural. A convicção de que é possível, por intermédio da educação, criar o "homem novo", politicamente desalienado e capaz de construir uma sociedade livre da exploração e da opressão, explicita-se no trecho a seguir, de versos curtos e contundentes:

$$
\begin{gathered}
\text { É preciso } \\
\text { este povo } \\
\text { ensinar } \\
\text { pr'a entender } \\
\text { quem o quer } \\
\text { explorar. } \\
\text { É preciso } \\
\text { fazer } \\
\text { despontar } \\
\text { deste solo } \\
\text { calcado } \\
\text { o homem novo. } \\
\text { É preciso } \\
\text { destruir } \\
\text { e acabar } \\
\text { com o peso } \\
\text { e opressão } \\
\text { colonial. }
\end{gathered}
$$

Em "O rasto da tua passagem", terceiro texto encontrado na coletânea", Borja da Costa se dirige diretamente ao colonizador português, denunciando a violência da ação colonial, que silenciou a razão do colo- 
nizado, sufocou sua cultura, abafou suas revoltas e torturou seus corpos. O tom do texto é duro, intenso e a interlocução é direta, não deixando margem para relativismos: "Saqueaste / assassinaste/ massacraste / pilhaste". Ao final, a revolta do colonizado se materializa na possibilidade de confrontar e vencer o colonizador, usando as mesmas armas anteriormente usadas por ele:

\author{
na ponta da baioneta \\ assinalaste $o$ rasto da tua passagem \\ na ponta da minha baioneta \\ marcarei na história a forma da minha \\ LIBERTAÇÃO
}

Com relação a esse poema, vale dizer que ele volta à cena na luta da resistência timorense contra o regime opressor da indonésia. O conteúdo dos versos finais é veiculado pelas forças da Resistência de diferentes formas, como em famoso muro fotografado no Distrito de Manatuto e que traz a mensagem: "Na ponta da minha baioneta escrevei a história da minha libertação".

O quarto e o quinto poema, respectivamente "Povo pobre" e "Kole lele mai (o que é que faz?)", aproximam-se pelo seu teor de questionamento sobre os responsáveis pela pobreza e pela fome de que padecem os timorenses. Ambos os textos buscam promover uma reflexão por parte dos colonizados, que são instados a se perguntar sobre as causas e os agentes de sua condição de miséria. Versos como "Somos filhos pobres, de gente pobre / todos somos pobres, de gente pobre / Por quê, por quem, por causa de quê? / por quê, por quem, por causa de quem?" (poema 4) e "quem, quem é que faz com que passes fome / quem, quem é que faz com que teu suor não seque / (...) O quê é que faz? Quem, quem, ao certo, quem? (poema 5) dão bem a medida da postura do poeta, que visa a conscientizar seus interlocutores - referidos como "irmãos", em "Povo pobre" - e instigá-los à luta pela libertação.

O poema 7, intitulado "O grito do soldado maubere", é o mais longo da série. Ele é dividido em oitos partes e pretende recobrir um período de 10 dias: da madrugada do dia 11 de agosto (de 1975), momento em que a UDT desencadeia uma ação armada contra a Fretilin, até o dia 20 do mesmo mês. Esses são dias terríveis, de enfrentamento militar extremamente violento entre as forças conservadoras da UDT e os soldados mauberes. Ao longo do texto, o poeta denuncia a conivência do governo 
português com os golpistas, repetindo a cada vez, em letras maiúsculas: “E O GOVERNO CONTINUA DE BRAÇOS CRUZADOS”. Ao final, palavras de ordem e de celebração da Fretilin, reconhecida como a organização legítima para a conquista da independência, são enunciadas:

\author{
NÃO ao assassínio \\ NÃO ao colonialismo \\ NÃO às garras dos vândalos na carne do Povo Maubere \\ E no solo de Timor-Leste \\ SIM com a FRETILIN \\ Para a LIBERTAÇÃO TOTAL.
}

O próximo poema, "Ela vencerá", é o oitavo do livro e é especialmente interessante pois se refere à mulher maubere, absolutamente objetificada pela ação colonial. Para essa mulher explorada, violada, traída, "tragicamente dilacerada", nos termos do poema, é imaginado um futuro de justiça e igualdade após a conquista da independência. $\mathrm{O}$ último verso, "ELA VENCERÁ", afirma a certeza da vitória e nos leva a considerar o estabelecimento de um paralelo entra a mulher e a terra timorense: ambas desejadas e aviltadas pelo colonizador português; ambas exploradas e, através a luta anticolonial, prestes a se libertar.

O nono poema, "Um minuto de silêncio", é um texto especialmente delicado, em que o poeta pede aos elementos da natureza - montes, aves, fontes, pedras, pássaros, ondas, ventos árvores, palmeiras, entre outros - um minuto de silêncio por aqueles que perderam a vida no conflito armado com a UDT, para que a proclamação da independência fosse possível. O texto foi inspirado em um momento histórico absolutamente significativo, no minuto de silêncio observado quando a bandeira da Fretilin foi içada em 28 de novembro de 1975:

Em 28 de Novembro de 1975 dá-se a Proclamação unilateral da Independência de Timor-Leste pela FRETILIN e pelo primeiro Presidente da República, Xavier do Amaral, assumindo o cargo de Primeiro-Ministro Nicolau Lobato, que viria a ser o primeiro líder da Resistência Armada. Com a proclamação da Independência tem também início a guerra civil. (GOVERNO DE TIMOR-LESTE)

Vale reproduzir a primeira estrofe do texto, cujo início e final se dão com a presença do verbo "calai", sugerindo o silêncio e a reverência devida aos heróis da guerra: 


\author{
Calai \\ Montes \\ Vales e fontes \\ Regatos e ribeiros \\ Pedras dos caminhos \\ E ervas do chão
}

Calai.

Por fim, destacamos o poema 13, intitulado "Estrela d'Alva". Trata-se de mais um texto em que um elemento natural é evocado em uma perspectiva de solidariedade para com o povo maubere. A estrela d'alva, nome popular do planeta Vênus, é ponto de orientação comum para populações insulares e aparece aqui como guia de todos os timorenses, ponto de luz a iluminar a consciência e os caminhos da população na construção imaginada de um futuro livre e mais igualitário:

\title{
Estrela d'Alva
}

Estrela d'Alva no céu

Ilumina a noite escura, Brilha sobre Timor Lorosa'e

Sobre todos nós.

Estrela d'Alva no céu

Vem orientar o caminho!

Vem mostrar o caminho certo

Que nos leve à luz

Vem iluminar a consciência de Timor

Vem abrir os seus olhos.

\section{Considerações finais}

Percorrer alguns dos poemas que compõem Borja da Costa - selecção de poemas / klibur dadolin evidencia a postura empenhada e militante do poeta, inscrita na perspectiva a partir da qual ele se posiciona diante do que elege como matéria literária. É então que o engajamento - ou o caráter de resistência dos textos - se aclara.

A dimensão de resistência política dos poemas, que enfatizam a especificidade cultural maubere e a necessidade de organização coletiva para a defesa dos interesses dos habitantes do território, dialoga com os parâmetros expressos na "Proclamação", documento produzido pelos 
membros da União dos Escritores Angolanos, por ocasião de sua fundação, em 1975. Nesse sentido, observa-se a pertinência da leitura comparativa entre textos que, escritos em momentos cruciais da história de países submetidos ao domínio colonial português, tematizam a resistência, o nacionalismo e os anseios de liberdade.

Em termos linguísticos, merece destaque o fato de que Borja da Costa tenha escrito seus poemas tanto em tétum como em português. Tal gesto expressa a profunda consciência política do autor e sua identificação com a cultura autóctone que desejava - e sabia ser necessário - preservar. Do ponto de vista discursivo, é interessante notar que os interlocutores dos textos poéticos muitas vezes vêm identificados: ora são os colonizados (timorenses comumente referidos como "irmãos"); ora são os colonizadores (agentes da opressão que precisam ser combatidos).

A leitura do conjunto de poemas permite identificar algumas marcas formais recorrentes, que estruturam o projeto literário do autor. São elas: os versos curtos; a pontuação abundante que visa conferir forte carga expressiva aos textos; as repetições e o uso de refrões; certa preocupação métrica, que dialoga com as regras da tradicional poesia timorense; a instauração de um eu coletivo, expressão de uma comunidade timorense imaginada; a presença de elementos da natureza, que aparecem identificados com os dramas e as aspirações do colonizado; a criação de imagens fortes, que denunciam a violência do processo colonial e da luta travada pela independência.

Importa destacar ainda que os textos de Borja da Costa acabaram se revestindo de atualidade e importância mesmo depois da independência de Portugal, dado que o povo timorense passa a vivenciar, a partir de 7 de dezembro de 1975, data do assassinato do poeta, as mazelas da ocupação indonésia. Os versos do poeta se ressemantizam no novo contexto, num percurso dramático que durará 24 anos.

\section{REFERÊNCIAS}

ABDALA Jr., Benjamin. Literatura, história e política: literaturas de língua portuguesa no século XX. Cotia: Ateliê Editorial, 2007.

. "A poesia além da Resistência”. In: Caderno Mais! Folha de S. Paulo. 12 
jan.1997. Disponível em: https://www1.folha.uol.com.br/fsp/mais/fs120109.htm . Acesso: 13 de março de 2018.

BOSI, Alfredo. "Narrativa e resistência”. In: Literatura e resistência. São Paulo: Companhia das Letras, 2002.

COSTA, Luís. Borja da Costa - Selecção de Poemas / Klibur Dadolin. Lisboa / Porto: LIDEL, 2009.

FERNANDES, Maria Julia. "Borja da Costa: um poeta e uma fundação. Quando florescer o arroz”. Revista Camões, N. 14. Timor Lorosa'e. Lisboa, Instituto Camões, 2001.p. 146-151.

GOVERNO DE TIMOR-LESTE. História de Timor-Leste. Disponível em: http://timor-leste.gov.tl/?p=29. Acesso: 27 de abril de 2018.

GUSMÃO, Xanana. Timor Leste - um povo, uma pátria. Lisboa: Colibri, 1994.

LIMA, Fernando. Timor - Da Guerra do Pacífico à desanexação. Macau, Instituto Internacional de Macau, 2002.

NETO, Agostinho. Sobre a literatura. Luanda: União dos Escritores Angolanos, 1978.

SOARES, Lucia Vidal. Texto lido pela autora na apresentação pública da obra "Borja da Costa - selecção de poemas". Lisboa, 2009. Retirado de https://www. academia.edu/8753219/Apresenta\%C3\%A7\%C3\%A3o_da_obra_Borja da Costa selec $\% \mathrm{C} 3 \% \mathrm{~A} 7 \% \mathrm{C} 3 \% \mathrm{~A} 30$ de poemas _. Acesso: 12 de março de 2018.

Recebido em: 29/09/2018

Aceito em: 12/03/2019 